Journal of Consumer Research, Inc.

Gaming with Mr. Slot or Gaming the Slot Machine? Power, Anthropomorphism, and Risk Perception

Author(s): Sara Kim and Ann L. McGill

Reviewed work(s):

Source: Journal of Consumer Research, Vol. 38, No. 1 (June 2011), pp. 94-107

Published by: The University of Chicago Press

Stable URL: http://www.jstor.org/stable/10.1086/658148

Accessed: 04/09/2012 23:37

Your use of the JSTOR archive indicates your acceptance of the Terms \& Conditions of Use, available at

http://www.jstor.org/page/info/about/policies/terms.jsp

JSTOR is a not-for-profit service that helps scholars, researchers, and students discover, use, and build upon a wide range of content in a trusted digital archive. We use information technology and tools to increase productivity and facilitate new forms of scholarship. For more information about JSTOR, please contact support@jstor.org. 


\title{
Gaming with Mr. Slot or Gaming the Slot Machine? Power, Anthropomorphism, and Risk Perception
}

\author{
SARA KIM \\ ANN L. MCGILL
}

\begin{abstract}
We propose that risk perceptions are systematically influenced by anthropomorphism. Anthropomorphism effects, however, are moderated by the individual's feelings of social power. People with low power perceive higher risk in playing a slot machine (study 1) and in getting skin cancer (study 2) when the risk-bearing entities (the slot machine and skin cancer) are highly anthropomorphized. In contrast, those with high power perceive greater risk when the entities are less anthropomorphized. We hypothesize these effects occur because those with high (low) power perceived a greater (lesser) degree of control over the anthropomorphized entity. In study 3 , we investigate the reverse effect that higher perceived risk may increase anthropomorphism for people with low power but decrease anthropomorphism for people with high power.
\end{abstract}

A recent IKEA advertisement made sport of people's inclination to anthropomorphize products. In the advertisement, a woman discards a red lamp in her trash. The lamp's shade is pointed toward the house and the "neck" and "head" of the lamp are angled enough to convey a human quality about the product. As night falls and the rain begins, the audience finds itself sympathizing with the discarded lamp and disliking the woman as she reads comfortably in her house under her spiffy new IKEA lamp. At just this moment, a man calls the audience out. "Many of you feel bad for this lamp," he says. "That is because you are crazy. It has no feelings. And the new one is much better." The surprise is terrific, but the wonder of the ad is its demonstration of just how readily people anthropomorphize. The ad works because the audience sees the old lamp

Sara Kim (skim12@chicagobooth.edu) is a doctoral student and Ann L. McGill (ann.mcgill@chicagobooth.edu) is Sears Roebuck Professor of Marketing and Behavioral Science at the Booth School of Business, University of Chicago, 5807 S. Woodlawn Ave., Chicago, IL 60637. Financial support from the Kilts Center for Marketing, University of Chicago, is gratefully acknowledged.

John Deighton served as editor and Patti Williams served as associate editor for this article.

Electronically published January 11, 2011 as a servant harshly dumped by a master. The lamp does not even have a humanlike face. The positioning of the shade, tipped toward the house, is enough to convey longing and loss. That is how fragile people's perceptions may be and how malleable their evaluations, depending on what they see. Hence, understanding anthropomorphism is critical to harnessing this important and pervasive tendency.

Anthropomorphism effects have recently captured social psychologists' attention, leading to investigations of why and when people anthropomorphize nonhuman entities (Epley, Akalis, et al. 2008; Epley, Waytz, et al. 2008; Epley, Waytz, and Cacioppo 2007). Consumer behavior researchers, however, have focused on consequences of anthropomorphism, especially on how anthropomorphizing affects liking of products (Aggarwal and McGill 2007). In this research, we extend the study of anthropomorphism by considering how it might affect other judgments beyond liking, specifically, how anthropomorphism affects risk perceptions and behavior. In our studies, we examine people's assessments of the risks associated with a gambling machine and a disease and how these risk perceptions might vary, depending on whether these risk-bearing entities are anthropomorphized. We further propose and find support for the hypothesis that the consumers' feelings of power moderate the effect of anthropomorphism. 


\section{THEORETICAL BACKGROUND}

\section{Anthropomorphism}

Anthropomorphism refers to the tendency to attribute humanlike characteristics, intentions, and behavior to nonhuman objects (Aggarwal and McGill 2007; Epley et al. 2007; Epley, Akalis, et al. 2008; Epley, Waytz, et al. 2008; Leyens et al. 2003). Early research on anthropomorphism focused on capacities of nonhuman objects by analyzing the extent to which anthropomorphism represents accurate insight versus fanciful illusion (Cheney and Seyfarth 1990; Hauser 2000; Morgan 1894). Recent research, however, has begun to investigate when and why people are likely to anthropomorphize (Epley et al. 2007; Epley, Akalis, et al. 2008; Epley, Waytz, et al. 2008). These studies describe factors that influence people's tendency to anthropomorphize nonhuman entities, such as objects or animals. A cognitionbased story suggests that an increase in accessibility to the human schema results in anthropomorphism (Aggarwal and McGill 2007; Epley et al. 2007). For example, perceived similarity between human behavior and the nonhuman movement of objects increases accessibility of human schema, which in turn increases anthropomorphism (Guthrie 1993; Morewedge, Preston, and Wegner 2007). A motivationbased story, however, posits that desire to understand the acts of nonhuman agents or the need for belongingness can determine the tendency to anthropomorphize (Epley et al. 2007; Epley, Waytz, et al. 2008). Compared to adults, young children lack understanding of nonhuman objects, so they are more likely to attribute life and mental states to nearly all objects in the environment (e.g., angry cloud or happy sun; Piaget 1929). Apart from such effectance motivation (need for understanding), need for belongingness also can be satisfied by making connections with two of the most commonly anthropomorphized nonhuman entities: pets and religious agents (Allen, Blascovich, and Mendes 2002; Epley, Akalis, et al. 2008; Siegel 1990).

A more recent stream of research has changed the focus from when and why people anthropomorphize to how anthropomorphism affects judgments and behavior. Most studies to date, however, suggest that anthropomorphism has a positive effect on judgments and behavior. According to those studies, anthropomorphism can enable a sense of efficacy with nonhuman entities, or it can increase emotional bonding with them, which can positively affect judgments of nonhuman entities. For example, people were more likely to cooperate and work with humanlike robots than with machinery robots (Kiesler and Goetz 2002). Also, participants showed more favorable attitudes toward a computerized desert survival task when more anthropomorphic faces and voices appeared in the interface (Burgoon et al. 2000).

Consumer behavior researchers also have been interested in how anthropomorphism affects consumers' judgments and behavior, although this stream of research has largely concentrated on the effects of anthropomorphized brands. For example, researchers have studied brand personality
(Aaker 1997) and consumer-brand relationships (Aggarwal 2004; Fournier 1998). Despite the prevalence of marketers' efforts to design anthropomorphic products and characters in advertisements to generate desired emotional reactions from consumers and, in turn, increase sales (Phillips 1996; Welsh 2006), research on the effects of anthropomorphizing the product as in the IKEA ad above is relatively rare. An exception is recent work by Aggarwal and McGill (2007), which examines anthropomorphism of the product itself. This research finds that people increase liking of the target product when a congruency exists between a marketer-activated human schema and characteristics of the product because people are more likely to see the metaphor. That is, people can see the product as the person the marketer has suggested. However, when the congruity is too low, consumers are less likely to anthropomorphize the product and in turn more likely to like the product less. Even though this research represents a rare examination of the effect of anthropomorphizing the product itself, it is still much like previous studies in its focus on when people are more likely to anthropomorphize and how liking judgments vary depending on the degree of anthropomorphism.

Our research, by contrast, shows important downstream consequences of anthropomorphism that go beyond simple liking of products with humanlike physical features. Further, this work demonstrates responses to anthropomorphized entities that suggest perceptions of these objects as actually human (or humanlike) as distinct from perceptions of these objects as ultimately inhuman but as being usefully described in human terms. The definition of anthropomorphism-as attributing humanlike attributes to nonhuman objects-allows for two distinct forms of anthropomorphism (see Guthrie [1993] for another three-part typology of anthropomorphism). One form of anthropomorphism relies on analogical reasoning and uses the human schema to structure, think about, and communicate characteristics of the nonhuman entities. The literature on brand personality and some work on the antecedents of anthropomorphism, especially that on effectance motivation, may be seen as this form of anthropomorphism. In this case, anthropomorphism is a process of inductive reasoning or a simple description of an observable appearance or behavior of nonhuman entities. For example, a brand that can be relied on to fulfill advertising promises may be described as trustworthy, analogous to a valued friend, but without really be seen as possessing the underlying values and strength of will of a person. Hence, in Aggarwal and McGill's work (2007), increased liking of a product with humanlike physical features may not have been observed because participants brought the brand to life but rather, as the authors argued, because participants were able to grasp the analogy to an activated human schema. The possibility of this somewhat limited form of anthropomorphism might explain why Yoon et al. (2006) observed neural dissociates between brand and person judgments.

However, anthropomorphism may go beyond recognition of surface similarities between objects and people (Waytz, 
Cacioppo, and Epley 2010). Attributing humanlike mental states is a second form of anthropomorphism, one that is a step closer to seeing nonhuman objects as being "really" human. This type of anthropomorphism can trigger social beliefs and perceptions afforded other human beings. Waytz et al. (2010) found that when people perceived a nonhuman entity to have a mind, they were more likely to treat the entity as a moral agent worthy of empathic care and concern. In this vein, Chandler and Schwarz (2010) demonstrated that people were less willing to replace a product when they saw it as having a humanlike mind. Even though this emerging stream of research recognizes important downstream consequences of anthropomorphism beyond the productperson metaphor, it still focuses on difference in judgments, depending on the degree of anthropomorphism.

Our research, by contrast, explores situations in which the same degree of anthropomorphism can color judgments differently, depending on the social beliefs and expectations of the consumer. We suggest that when consumers attribute humanlike mental capacities to nonhuman objects, they will apply beliefs and knowledge about their social world to the object world, and consumers with different social concepts will perceive the same anthropomorphized object differently. Hence, we measure application of social beliefs and judgments toward nonhuman entities as a consequence of anthropomorphism as evidence of whether consumers perceive an anthropomorphized product to possess a humanlike mind. Also, in contrast with previous work, we will investigate the effect of anthropomorphism on other types of judgments beyond liking. We are particularly interested in how anthropomorphism influences risk perceptions.

The central hypothesis of this research is that anthropomorphizing a product causes consumers to apply social expectations and beliefs they would not normally apply to an inanimate entity. For example, for consumers considering playing a slot machine, our hypothesis is that their perception of risk (and so their willingness to play) would depend on whether they see the machine as being human. If the product is not anthropomorphized, risk assessments should follow from expectations about the machine's settings and calibration, that is, from nonsocial considerations. However, if the entity is anthropomorphized, risk assessments should follow from beliefs and expectations about human interaction, such as consumers' perceived social power over others, their degree of trust in others, their sense of personal need, and their view of others as kind or altruistic. Hence, anthropomorphism may have different effects, depending on the model of social interaction brought to mind at the time of the decision. In our research we focus specifically on perceived social power.

\section{Power, Control, and Risk Judgment}

Power is a fundamental sociological concept and a central motivating force in social interactions (Fiske and Dépret 1996; Keltner, Gruenfeld, and Anderson 2003). Hence, power is an appropriate test of our theorizing regarding the potential influence of social factors on the assessment of anthropomorphized entities. Our study of power also coincides with current interest in the psychology literature on the consequences of power (Fast et al. 2009; Galinsky, Gruenfeld, and Magee 2003; Keltner et al. 2003), and it complements this work by considering the influence of power on nonhuman entities. In addition, understanding the influence of power may have important practical implications for marketers because power perceptions are contextually malleable. Therefore, if the influence of social power can be properly understood, marketers might be able to sway customers' power perceptions in accordance with their strategies. For example, briefly recalling past experience in which one felt powerful or powerless (Galinsky et al. 2003) or a short role play (Brinol et al. 2007) may be enough to change one's current perception of social power, which in turn influences cognition, emotion, and behavior.

Most social psychology studies define power as an individual's relative ability to control the states of others in accordance with his or her own will (Fiske 1993; Thibaut and Kelley 1959). Further, the causal relationship between perceived power and feelings of control is bidirectional. People believe they have more power over others when they have more control (Copeland 1994; Dépret and Fiske 1993; Thibaut and Kelley 1959), and people believe they have more control when they feel more powerful (Bargh et al. 1995; Croizet and Claire 1998; Fast et al. 2009; Galinsky et al. 2003). This research particularly focuses on the latter link, that is, how feelings of power lead to perceived control.

In particular, we explore how feelings of power arising from sources unrelated to a target entity, for example, recalling past experiences, may nevertheless affect perceived control over that entity, especially when it is anthropomorphized. As such, we can view the effect of anthropomorphism on risk assessment as an "illusion of control" (Langer 1975). Previous research on illusory control shows that when a task has some characteristics that people associate with personal skill, individuals sometimes behave as if they can influence outcomes that are actually the result of pure chance (Langer 1975; Strickland, Lewicki, and Katz 1966; Thompson, Armstrong, and Thomas 1998; Wohl and Enzle 2002). For example, people believe they are more likely to attain a positive outcome when they roll a die themselves than when an experimenter does or when they put in their winning number than when a random number generator gives them the number (Langer 1975). This research proposes that anthropomorphism can also increase or decrease illusory control through the (mis-) application of social power onto nonhuman objects.

In sum, we propose that people will apply feelings of social power when thinking about a risk-bearing mechanism (e.g., a slot machine or a disease) that is anthropomorphized but not when the mechanism appears to lack human traits. Even when perceived power derives from sources unrelated to the risk-generating entity, people might apply this feeling when they see the entity as human and therefore subject to the same social processes. Specifically, we argue that people who feel powerful transfer this feeling of mastery to the 
anthropomorphized entity, believe they can control it, and so feel less risk. In contrast, people who are low in power feel at the mercy of the entity, feel lower control over the entity, and so feel greater risk.

We examine this effect of perceived power on risk perceptions for risk-bearing entities in studies 1 and 2 . The first study concerns a slot machine, and the second study, a conceptual replication to a less pleasurable domain, concerns a disease. Study 2 also provides evidence about the underlying process by showing that perceived control over the nonhuman entity mediates the interactive role of power and anthropomorphism. In our third study, we investigate the reverse effect in which risk perception influences the anthropomorphism tendency. The idea behind this third study is that if people experience outcomes that seem to follow a pattern they associate with their human interactions, they will see a human entity as being behind those outcomes. Specifically, we examine whether people with high power increase anthropomorphism when they perceive low risk (vs. high risk)—seeing the risk-bearing entity as more humanlike - and whether those with low power increase anthropomorphism tendency when they perceive high risk (vs. low risk).

\section{EXPERIMENT 1}

Experiment 1 tested whether anthropomorphism increased (decreased) risk perception of playing the slot machine for respondents with low (high) power perception. The experiment employed a 2 (power: high vs. low) $\times 2$ (humanization: high vs. low) between-subjects design.

\section{Method}

Sixty-one undergraduate and graduate students (31 women) from a private midwestern university in the United States participated in this experiment for monetary compensation. The study consisted of two phases: the power manipulation phase and the risk perception measurement phase. First, participants engaged in the power manipulation task and then were guided to a computer room for a presumably unrelated study. A full-size picture of a slot machine was loaded onto the computer screen in advance, but the screen was turned off. Participants were asked to turn on the computer screen in front of them and to look at the picture for a while. Then they read information about a slot machine game. Finally, we asked them to answer questions involving risk perception and behavioral intention to play the slot.

Power Manipulation. We manipulated power by asking participants to describe their own experience in which they felt powerful (vs. powerless) - a method established in social psychology (Galinsky et al. 2003). More specifically, participants in the high-power condition read the following statement: "When did you feel powerful? Please, recall your past experience in which you had power over another person or several people. You can feel powerful when you think that you are influential on other's beliefs and behaviors. You also can feel powerful when you are in charge of something for others. Please describe your own experience in which you had power. What happened? How did you feel? Please try to recall the experience as if you were experiencing it now." Participants in the low-power condition read the following statement: "When did you feel powerless? Please, recall your past experience in which someone else had power over you. You can feel powerless when you think that someone else is influential on your beliefs and behaviors. You also can feel powerless when someone else is in charge of something for a group you belong. Please describe your own experience in which you felt powerless. What happened? How did you feel? Please try to recall the experience as if you were experiencing it now."

Anthropomorphism Manipulation. Participants in the risk measurement phase learned that the purpose of the study was to understand people's attitudes and experiences in a casino. They were asked to imagine that they were in a casino for gambling and had found an available slot machine to play (the one on the computer monitor). Participants in the high-anthropomorphism condition saw a slot machine picture that looked more like a human than did those in the low-anthropomorphism condition. We manipulated the degree of anthropomorphism by changing only the arrangement of rectangular bars on the upper part of the machine (see fig. 1; the left picture is the more highly anthropomorphized slot machine). In the high-anthropomorphism condition, we arranged three small rectangles to form two eyes and a mouth. In the low-anthropomorphism condition, we connected the three rectangles and placed them on top of the machine. We kept the rest of the body the same for both conditions. Participants also received information about the slot machine game (how to play, the winning combinations), which was the same for both the high- and the low-anthropomorphism conditions.

Dependent Variables. First, to measure risk perception, each participant indicated how risky the slot game seemed to be $(1=$ not at all risky; $7=$ very risky), how likely they were to win at all $(1=$ very unlikely; $7=$ very likely), and if they did win, how big they thought the prize would be ( $1=$ very small; $7=$ very big). Then they also indicated to what extent they were willing to play the game ( $1=$ not at all; $7=$ very much). For the manipulation check of anthropomorphism, participants were asked to what extent they thought the slot they saw on the screen looked like a human ("It looks like a person," "It seems almost as if it has free will," and "It seems almost as if it has intentions"; 1 = disagree; 7 = agree).

Additional Control Measures. In addition to the primary measures of interest, we also asked all participants to indicate general risk-taking tendency ("I generally like to take a risk"; 1 = disagree; 7 = agree), general liking of playing slots ("I generally like to play slots"; 1 = disagree; $7=$ agree), attention to information about the game $(1=$ paid little attention; $7=$ paid a lot of attention to the in- 
FIGURE 1

SLOT MACHINE ANTHROPOMORPHISM (EXPERIMENT 1)
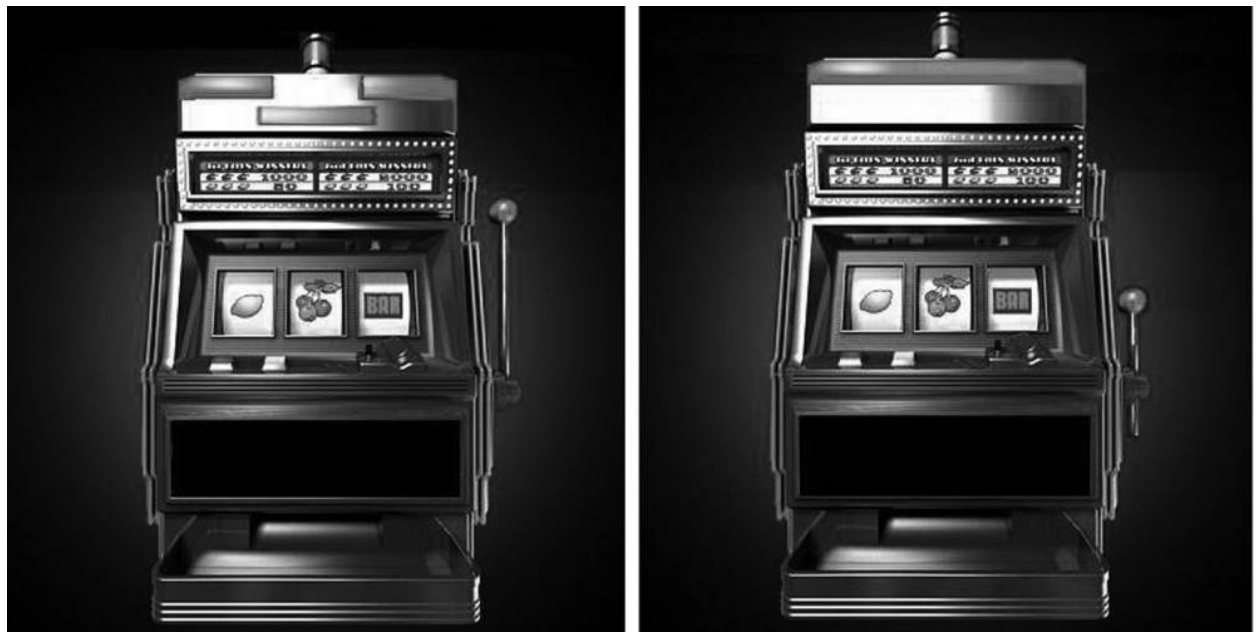

NOTE._Left, more highly anthropomorphized slot machine. Color version available as an online enhancement.

formation), attention to picture $(1=$ paid little attention; 7 $=$ paid a lot of attention to the picture), current $\operatorname{mood}(1=$ feel bad; 7 = feel good), and their current level of arousal ( $1=$ feel depressed; $7=$ feel excited $)$ as control variables, in order to ensure that these factors did not cause the results.

\section{Results}

Manipulation Check and Control Measures. We averaged three items to measure the degree of anthropomorphism (looks like a person, has free will, has intentions; $\alpha$ $=0.83$ ). We conducted a 2 (power: high vs. low) $\times 2$ (anthropomorphism: high vs. low) between-subjects ANOVA on perception of the slot. As we intended, participants in the high-anthropomorphism conditions indicated that the slot machine looked more like a human than did those in lowanthropomorphism conditions $\left(M_{\mathrm{hi}}=2.88, M_{\mathrm{low}}=1.67\right.$; $F(1,57)=12.70, p<.01)$. No other effects were significant ( $p$ 's $>.20)$. We also conducted a 2 (power: high vs. low) $\times 2$ (anthropomorphism: high vs. low) between-subjects ANOVA on each of the control measures. The analyses showed that power perception or anthropomorphism did not affect participants' general risk-taking tendency, general liking of playing slots, attention to information about the game, attention to picture, mood, and arousal (all $p$ 's $>.19$ ).

Hypothesis Testing. We conducted a 2 (power: high vs. low) $\times 2$ (anthropomorphism: high vs. low) ANOVA in which willingness to play the game served as a dependent variable. The result revealed a significant interaction effect $(F(1,57)=19.63, p<.01)$ but no other significant effects ( $p$ 's > .20; see fig. 2). Specific contrasts revealed that participants in the high-power conditions were more willing to play the game when the slot machine looked more like a human $\left(M_{\text {hi an }}=4.13, M_{\text {low an }}=2.27 ; F(1,57)=16.36, p\right.$ $<.01)$. However, participants in the low-power conditions indicated that they were less likely to play the game when the slot looked more like a human $\left(M_{\text {hi an }}=2.71, M_{\text {low an }}=\right.$ $3.71 ; F(1,57)=4.89, p<.05)$. Looking at the other pair of contrasts, we found, consistent with our theorizing, that high-power participants were more likely than low-power participants to play the game when the machine looked like a person $\left(M_{\text {hi pow }}=4.13, M_{\text {low pow }}=2.71 ; F(1,57)=10.18\right.$, $p<.01)$. We also found a significant difference between

\section{FIGURE 2}

THE EFFECT OF POWER AND ANTHROPOMORPHISM ON WILLINGNESS TO PLAY THE SLOT GAME (EXPERIMENT 1)

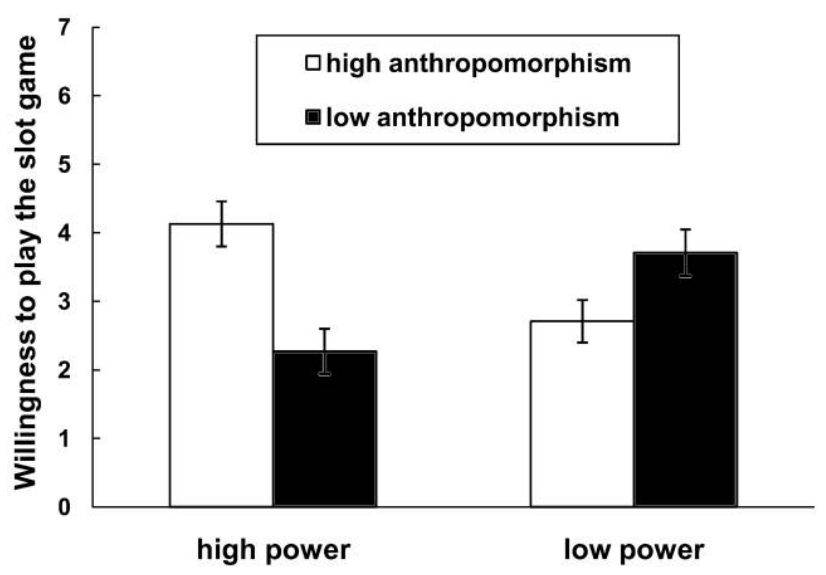


high- and low-power participants in the low-anthropomorphism condition $\left(M_{\text {hi pow }}=2.27, M_{\text {low pow }}=3.71 ; F(1,57)\right.$ $=9.49, p<.01)$. That is, those in high power were less likely to play the game with the low-anthropomorphized machine compared to those in low power. Although we did not predict this effect, it may be explained within our same broad framework by suggesting that people who are low in social power feel most at ease, that is, are in their comfort zone in the world of objects, whereas those with high social power feel out of their depth. Hence, the low-social-power people feel they can master the objectified slot machine, while the high-social-power people feel they cannot.

Risk Perception. In order to compute the risk-perception component, we averaged three items to measure risk perception (riskiness, likelihood to win, and expected prize value; $\alpha=0.67$ ). The scales for likelihood to win and expected prize value were reversed. That is, greater scores on these items indicated greater risk perception. According to a power-by-humanization two-way ANOVA, participants with low power perceived greater risk than those with high power, even though the difference was only marginally significant $\left(M_{\text {hi pow }}=4.77, M_{\text {low pow }}=5.11 ; F(1,57)=2.74\right.$, $p=.10)$. This main effect of power is consistent with previous literature demonstrating that power increases controllability over the situation (Bargh et al. 1995; Fast et al. 2009; Galinsky et al. 2003). However, such application of power was qualified by the significant interaction $(F(1,57)$ $=7.36, p<.01$; see fig. 3). As expected, participants with high power perceived the game as less risky when the slot looked more like a human $\left(M_{\mathrm{hi} \text { an }}=4.53, M_{\text {low an }}=5.02\right.$; $F(1,57)=2.93, p<.10)$. However, participants with low power perceived the game as riskier when they saw human features in the picture $\left(M_{\mathrm{hi} \text { an }}=5.41, M_{\mathrm{low} \text { an }}=4.81 ; F(1\right.$, $57)=4.54, p<.05)$. For the other pair of contrasts, consistent with our theory, the powerful perceived lower risk than the powerless in the high-anthropomorphism condition $\left(M_{\text {hi pow }}=4.53, M_{\text {low pow }}=5.41 ; F(1,57)=10.05, p<\right.$ $.01)$. However, different from willingness to play the game, in the case of risk perception, difference between the powerful and the powerless was not significant in the low-anthropomorphism condition $\left(M_{\text {hi pow }}=5.02, M_{\text {low pow }}=4.81\right.$; $F(1,57)=0.53$, NS).

Mediation Analyses. In order to test whether risk perception mediates the interactive effect of power and anthropomorphism on willingness to play, we conducted a mediated moderation analysis based on Muller, Judd, and Yzerbyt (2005). If risk perception indeed mediates the interactive effect of power and anthropomorphism on willingness to play, we should observe (1) a significant interaction effect of power and anthropomorphism on willingness to play and (2) a significant interaction effect of power and anthropomorphism on risk perception. Further, (3) when we include both risk perception and the interaction term (power $\times$ anthropomorphism), risk perception should remain significant, but the interaction term should reduce in significance. As we predicted, the analysis revealed a significant
FIGURE 3

THE EFFECT OF POWER AND ANTHROPOMORPHISM ON RISK PERCEPTION OF THE SLOT GAME (EXPERIMENT 1)

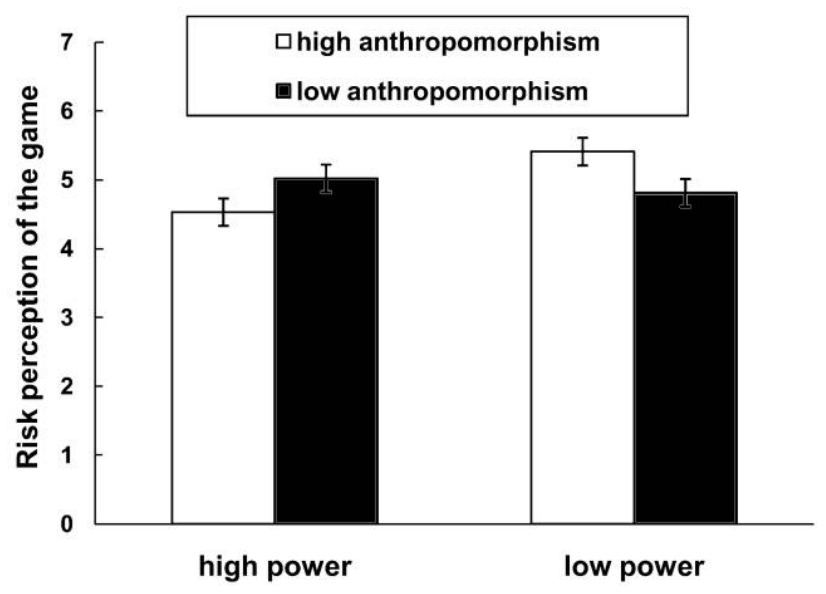

effect of the interaction between power and anthropomorphism on willingness to play $(b=0.72, \mathrm{SE}=0.16, t(57)$ $=4.43, p<.01$ ), a significant negative effect of risk perception on willingness to play $(b=-0.67, \mathrm{SE}=0.21$, $t(59)=-3.23, p<.01)$, and a significant effect of interaction between power and anthropomorphism on risk perception $(b=-0.28, \mathrm{SE}=0.10, t(57)=-2.72, p<.01)$. In a regression, which included power, anthropomorphism, power $\times$ anthropomorphism, risk perception, and risk perception $\times$ power as predictors of willingness to play (eq. 6 from Muller et al. 2005), the effect of risk perception was still significant $(b=-0.43, \mathrm{SE}=0.21, t(55)=-2.06$, $p<.05)$, but the interactive effect of power and anthropomorphism reduced in significance $(b=0.61, \mathrm{SE}=0.17$, $t(55)=3.62, p<.01$; Sobel's $z=1.66, p<.10)$. Thus, risk perception mediated the effect of interaction between power and anthropomorphism on willingness to play the slot.

\section{Discussion}

Experiment 1 presents several noteworthy findings. First, replicating previous research (Burgoon et al. 2000; Kiesler and Goetz 2002), it shows that anthropomorphism increased liking of interacting (gaming in this case) with the anthropomorphized entity (the slot machine). Second, extending previous research, our study shows that $(a)$ this positive anthropomorphism effect occurred only for participants with high rather than low power, and $(b)$ risk perception, which represents perceived control over the machine, mediated the anthropomorphism effects. Different from risk-free nonhuman objects in the previous studies (Burgoon et al. 2000; Kiesler and Goetz 2002; Turkle 2000), a slot machine game bears risk, and our findings indicate that when risk perception determines intention to interact with risk-generating en- 
tities, anthropomorphism effects are not always positive. Instead, the effect of anthropomorphism varies, depending on an individual's power perception at that moment.

Moreover, note that subtle changes in the appearance of the slot machine were enough to alter individuals' risk perception. In this study, the only change in the machine was the appearance of a decorative red strip at the top of the machine (one long bar or three shorter red bars positioned as if they were two eyes and a mouth). A manipulation check confirmed that this small change in appearance was sufficient to produce a difference in the degree to which participants anthropomorphized the slot machine. Finally, across the conditions, we did not observe any differences in general risk-taking tendency, general liking of playing slots, attention, mood, and arousal, suggesting that differences in processing styles are unlikely to account for our effects.

\section{EXPERIMENT 2}

One purpose of experiment 2 was to replicate the anthropomorphism effects we observed in experiment 1 . This replication is important because the interaction of anthropomorphism and power on risk perception achieved only marginal significance in the prior study. Experiment 2 also extends our findings to a new domain. Unlike a slot machine, which is a relatively pleasurable risk-bearing entity (games are for fun after all), the risk-bearing entity in our second study is not pleasurable, specifically, skin cancer. Finally, this study further tests our theory by providing process evidence that people apply their perception of social power to highly anthropomorphized objects by changing perceived control over them. We expected that high social power would increase perceived control over a highly humanized skin cancer, which in turn would decrease perceived risk, whereas low power would decrease perceived control, which in turn would increase risk perception toward the highly humanized skin cancer.

\section{Method}

Power Manipulation. Eighty-four undergraduate and graduate students (41 women) from the same university as in experiment 1 participated in this experiment for monetary compensation. We manipulated power perception as in experiment 1. Participants wrote about an experience in which they felt powerful (vs. powerless).

Anthropomorphism Manipulation. Participants were then asked to wait while the experimenter prepared the next study. While they waited, we asked them whether they wanted to read and provide some feedback on a healthrelated message that had recently been released. All the participants agreed to do so. The message was a description of a type of skin cancer. Participants in the high-anthropomorphism condition read the following message in which skin cancer is described as if it has humanlike intentions to hurt people:
Skin cancers are the most common members of the cancer family-almost like a crime family. It is estimated that over 1 million new people are attacked by these criminals. The annual rates of all new members of them are increasing each year, representing a growing public concern. The most common warning sign of their activity is a change in the appearance of the skin, such as a new growth or a sore that will not heal. There are some different types of family members, but the most common and potentially dangerous member is:

\section{$B$ cell carcinoma:}

This member is the most common among the cancer family ( $90 \%$ of all skin cancer in the U.S). According to the U.S. National Institutes of Health, exposure to ultraviolet (UV) radiation from the sun is the main cause. The growth of this member is not only because of accumulated sun exposure but also because of intermittent sun exposure like that received during vacation, especially early in life (between 15 to 25). This cancer begins to grow as a small, dome-shaped bump and often lives surrounded by small, superficial blood vessels. This member grows slowly, taking months or even years to become noticeable. Sometimes, this cancer can damage and disfigure the eye, ear, or nose if it grows nearby.

Snow on the ground doesn't mean you don't have to worry about sun exposure. Skin cancers can come to you even in winter months. When they come, they don't care that you are just starting out in life and family members range from the petty thief to outright killers. Protection from the sun is the best way to prevent this disease.

Participants in the low-anthropomorphism condition read the following message:

Skin cancers are the most common form of cancers. It is estimated that over 1 million new cases occur annually. The annual rates of all forms of skin cancer are increasing each year, representing a growing public concern. The most common warning sign of skin cancer activity is a change in the appearance of the skin, such as a new growth or a sore that will not heal. There are some different forms of skin cancer, but the most common and potentially serious form is:

\section{$B$ cell carcinoma:}

It is the most common form of skin cancer category (90\% of all skin cancer in the U.S). According to the U.S. National Institutes of Health, exposure to ultraviolet (UV) radiation from the sun is the main cause. The development of this cancer is not only because of accumulated sun exposure but also because of intermittent sun exposure like that received during vacation, especially early in life (between 15 to 25). This cancer begins to develop as a small, dome-shaped bump and is often covered by small, superficial blood vessels. It develops slowly, taking months or even years to become sizable. Sometimes, this cancer can damage and disfigure the eye, ear, or nose if it occurs nearby.

Snow on the ground doesn't mean you don't have to worry about sun exposure. Skin cancers can happen to you even in winter months. These diseases can strike people just starting out in life and their effects can range from taking a small 
measure of health to fatality. Protection from the sun is the best way to prevent this disease.

Dependent Variables. After reading the message, participants rated their perceived risk associated with skin cancer (serious, life threatening, and risky; $1=$ not at all; $9=$ very). Then, they indicated their perceived control over skin cancer. The four measurement items of control perception consisted of two subcategories: perceived control before getting the disease ("I believe I can effectively resist this disease" and "This disease has little chance of taking hold in me"; 1 = disagree; 7 = agree) and perceived control after getting the disease ("If I get this disease, I believe I could fight it off quickly" and "If I get this disease, it will not get the better of me"; $1=$ disagree; $7=$ agree). Participants also indicated the extent to which they felt skin cancer seemed to be like a human ("It sounds almost as if it has intentions" and "It sounds almost as if it has free will"; 1 $=$ disagree; $7=$ agree). We used different items to measure the degree of anthropomorphism because unlike in experiment 1 , anthropomorphism in this experiment was not about appearance; rather, it was about humanlike intentions.

Additional Control Measures. Finally, we measured control variables. All participants indicated their interest in skin care ("In general, I care about my skin" and "In general, I'm interested in skin care products"; $1=$ disagree; $7=$ agree), subjective knowledge about skin cancers ("I think I'm knowledgeable about skin cancers" and "I already knew a lot of information about skin cancers"; $1=$ disagree; 7 $=$ agree $)$, attention to the ads $(1=$ paid little attention; 7 $=$ paid a lot of attention to the information), mood $(1=$ feel bad; 7 = feel good $)$, and arousal $(1=$ feel depressed; 7 = feel excited).

\section{Results}

Manipulation Check and Control Measures. We averaged two items to measure anthropomorphism: humanlike intentions and free will $(\alpha=.83)$. Then, we conducted a 2 (power: high vs. low) $\times 2$ (anthropomorphism: high vs. low) between-subjects ANOVA with anthropomorphism perception as a dependent variable. The analysis revealed that participants in high-anthropomorphism conditions indicated that skin cancer sounded more like a disease with humanlike intentions and free will than did those in lowanthropomorphism conditions $\left(M_{\text {hian }}=4.95, M_{\text {lowan }}=3.80\right.$; $F(1,80)=9.88, p<.01)$. No other effects were significant ( $p$ 's $>.20$ ), indicating successful manipulation. In addition, 2 (power: high vs. low) $\times 2$ (anthropomorphism: high vs. low) ANOVAs revealed that interest in skin care, subjective knowledge in skin cancers, attention to the ads, mood, and arousal did not explain the effects (all $p$ 's $>.20$ ).

Risk Perception. We predicted that participants with low power would think of skin cancer as a more serious, dangerous disease if it was highly humanized, whereas those with high power would show the opposite pattern. In order to test this prediction, a 2 (power: high vs. low) $\times 2$ (anthropomorphism: high vs. low) ANOVA was conducted. Consistent with prior research on power, participants with low power (vs. high power) thought skin cancer was a riskier, more serious disease, although the effect was not significant $\left(M_{\text {hi pow }}=6.54, M_{\text {low pow }}=7.02 ; F(1,80)=1.93\right.$, $p=.16)$. However, more important and consistent with our prediction, the interaction between power and anthropomorphism was significant $(F(1,80)=6.49, p=.01$; see fig. 4). As predicted, participants with high power thought skin cancer was a riskier, more serious disease when it was less humanized $\left(M_{\text {hi an }}=6.08, M_{\text {low an }}=7.00 ; F(1,80)=\right.$ $3.06, p=.08$ ), whereas those with low power evaluated skin cancer as a riskier disease when it was highly humanized $\left(M_{\mathrm{hi} \mathrm{an}}=7.45, M_{\text {low an }}=6.59 ; F(1,80)=3.54, p=\right.$ .06). Consistent with our theorizing, we also found highpower participants thought that the disease was less risky than did low-power participants when it was highly anthropomorphized $\left(M_{\text {hi pow }}=6.08, M_{\text {low pow }}=7.45 ; F(1,80)=\right.$ $7.63, p<.01)$. However, toward the less anthropomorphized skin cancer, risk perception was not significantly different between the powerful and the powerless, which is consistent with experiment $1\left(M_{\text {hi pow }}=7.00, M_{\text {low pow }}=6.59 ; F(1\right.$, 80) $=0.68, p>.40)$.

Control Perception. Our theory posits that people apply their social beliefs toward anthropomorphized entities; thus, those with high power feel greater control over highly anthropomorphized entities just as they would feel in a social context, whereas those with low power feel less control over highly anthropomorphized entities. To test this prediction, a 2 (power: high vs. low) $\times 2$ (anthropomorphism: high vs. low) ANOVA was conducted with control perception $(\alpha=.71)$ serving as a dependent variable. In this analysis, only the interaction between power and anthropomorphism was significant $(F(1,80)=9.56, p<.01$; see fig. 5$)$. Planned

\section{FIGURE 4}

THE EFFECT OF POWER AND ANTHROPOMORPHISM ON RISK PERCEPTION OF SKIN CANCER (EXPERIMENT 2)

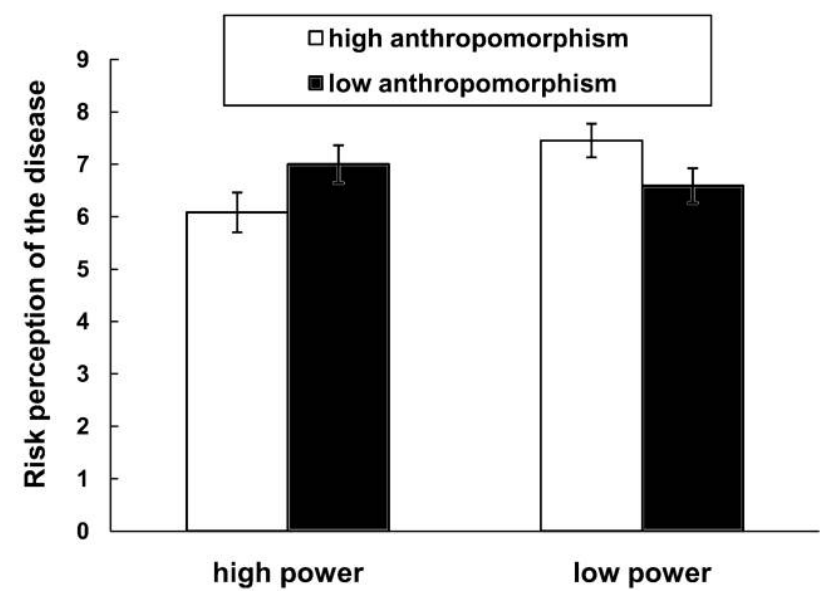


FIGURE 5

THE EFFECT OF POWER AND ANTHROPOMORPHISM ON CONTROL PERCEPTION TOWARD SKIN CANCER (EXPERIMENT 2)

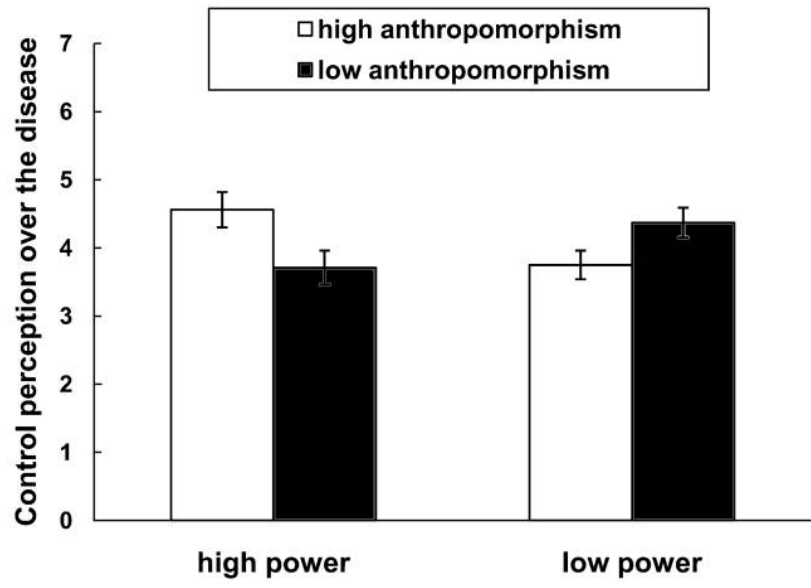

contrast analysis revealed, as predicted, that participants with high power indicated greater control perception over the highly anthropomorphized disease $\left(M_{\text {hi an }}=4.56, M_{\text {low an }}=\right.$ $3.71 ; F(1,80)=5.59, p<.05)$. However, those with low power felt lower control over skin cancer when it was highly humanized $\left(M_{\text {hi an }}=3.75, M_{\text {low an }}=4.37 ; F(1,80)=3.98\right.$, $p<.05)$. For the other contrasts, consistent with our theory that people will apply their social beliefs into highly anthropomorphized entities, participants with high (vs. low) power felt that they had greater control over skin cancer when it was highly anthropomorphized $\left(M_{\text {hi pow }}=4.56\right.$, $\left.M_{\text {low pow }}=3.75 ; F(1,80)=5.73, p=.01\right)$. In addition, we also observed a significant difference between high and low power in the low-anthropomorphism condition $\left(M_{\text {hi pow }}\right.$ $\left.=3.71, M_{\text {low pow }}=4.37 ; F(1,80)=3.91, p=.05\right)$. As we speculated in the first experiment, it is possible that this finding reflects greater comfort felt by low-power people in the world of objects.

Mediation Analyses. In order to see whether control perception mediates the interaction effect between power and anthropomorphism on risk perception, we again conducted a mediated moderation analysis as in experiment 1 (Muller et al. 2005). The mediated moderation analysis showed a significant effect of the interaction between power and anthropomorphism on risk perception $(b=-0.45$, SE $=0.18, t(80)=-2.55, p=.01)$, a significant negative effect of control perception on risk perception $(b=-0.55$, $\mathrm{SE}=0.15, t(82)=-3.68, p<.01)$, and a significant effect of interaction between power and anthropomorphism on control perception $(b=0.37, \mathrm{SE}=0.12, t(80)=3.09, p$ $<.01)$. When control perception was included as a covariate examining the interactive effect between power and anthropomorphism on risk perception, the effect of control perception was still significant $(b=-0.40, \mathrm{SE}=0.17, t(78)$
$=-2.39, p<.05)$, but the interaction reduced in significance $(b=-0.31, \mathrm{SE}=0.18, t(78)=-1.71, p=.09$; Sobel's $z=1.87, p=.06$ ). Therefore, control perception mediated the interaction effect between power and anthropomorphism on risk perception.

\section{Discussion}

By replicating the findings of experiment 1 while using a different manipulation of anthropomorphism and a different target, experiment 2 provides converging evidence toward our conceptual framework. In experiment 1 , whether the nonhuman entity (the slot machine) had a humanlike face determined the degree of anthropomorphism. By contrast, in experiment 2, participants perceived different degrees of anthropomorphism, depending on whether the riskbearing entity (skin cancer) was described as having a humanlike intention to harm people. The data again demonstrated that power perception moderated the effect of anthropomorphism on risk perception. Participants with low power perceived greater risk from the highly anthropomorphized skin cancer, whereas those with high power perceived lower risk from it. Furthermore, the interactive effect of power and anthropomorphism on risk perception was mediated by perceived control. High power increased control perception and so lowered perceived risk, whereas low power decreased control perception and so increased perceived risk, but only when skin cancer was described as if it had humanlike intentions.

\section{EXPERIMENT 3}

Our first two experiments showed that participants with low power felt greater risk when the risk-bearing entity was highly anthropomorphized, whereas those with high power felt lower risk toward the highly humanized entity. Our explanation for this effect is simple: once an object is anthropomorphized, people think about it according to familiar social roles, norms, and expectations. Hence, participants with low power acted as if they believed they would be at the mercy of anthropomorphized entities, whereas participants with high power appeared to think they could bend these entities to their will. In study 3 , we look further into the application of social perceptions on objects. In this study, we test the hypothesis that people's power perceptions coupled with their outcomes will influence their tendency to anthropomorphize. The idea here is that people infer humanity from the way these objects appear to be "acting" toward them. If people feel high power and the object appears to be giving them what they want, they anthropomorphize the object because it is acting the way other people would act toward a high-power person. By contrast, if people feel low power and the object is giving them what they want, they are less likely to anthropomorphize the object. After all, if the object were a person, low-power people would not expect to get their way. However, if things go poorly for a low-power person, the individual may sense the presence of another person. Hence, in experiment 3, we 
will show the reverse effect (in terms of direction of causation) of the first two studies, specifically that individuals with low power will increase anthropomorphism when they feel greater risk, whereas those with high power will increase anthropomorphism when they feel less risk. Risk perception will be manipulated with winning versus losing the slot machine game. We predict that people with high power will be more likely to anthropomorphize the slot after they win, whereas people with low power will be more likely to anthropomorphize the slot after they lose.

\section{Method}

Seventy-nine students (33 women) from the same university as the first two studies participated in this experiment for monetary compensation. As in the previous two experiments, participants first wrote about an experience in which they felt either powerful or powerless, depending on the condition. Then for a presumably unrelated study, experimenters asked participants to play a slot machine game 10 times. A screen depicted the slot machine they were to play (see fig. 6). We intended the appearance of this machine to be ambiguous, lacking the "facial" features of the anthropomorphized machine in study 1 , which had design elements we arranged to look like eyes and a mouth (refer back to fig. 1). However, this machine had more potential to be anthropomorphized than the machine in the object condition of that study because the bar at the top of the machine was not solid. People could interpret the three components as facial features.

Participants learned that each time they pressed a button they would get a combination of three symbols. If the combination of symbols included at least one of five winning symbols, they would win, and if they won more than five of 10 games, they would receive a prize at the end of experiment. Experimenters also told them that they had about a $50 \%$ chance of winning the prize. The participants then played the game. The results were already programmed, so half of the participants won the game seven times, which means they won the prize, whereas the other half lost the game seven times, which means they did not win the prize. The prize was a chocolate bar, but participants did not know what the prize was until they finished the game.

Dependent Variables. After playing the game, participants received a questionnaire that asked them first to choose which of two photos of slot machines they thought was more similar to the one they had played (see fig. 7). The photo of the machine at the lower end of the scale had served as our object condition in study 1 , whereas the photo of the machine at the high end of the scale had served as our anthropomorphism condition. Hence, this 9-point scale served as our measure of anthropomorphism, with a greater number indicating greater anthropomorphism.

Additional Control Measures. All participants indicated their general risk-taking tendency ("I generally like to take a risk"; 1 = disagree; 7 = agree), general liking
FIGURE 6

PHOTO OF THE SLOT MACHINE PARTICIPANTS PLAYED (EXPERIMENT 3)

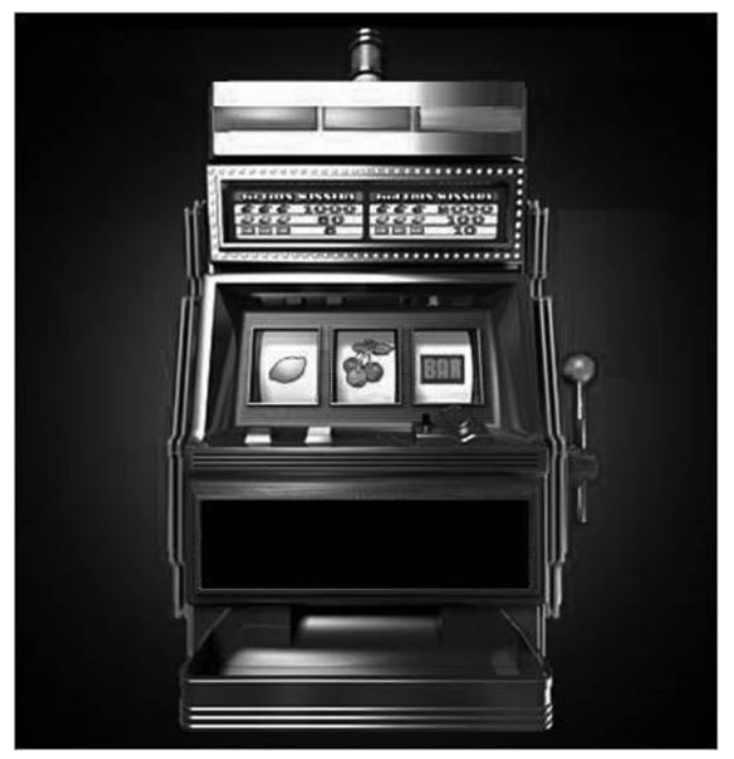

NotE.-Color version available as an online enhancement.

of playing slots ("I generally like to play slots"; $1=$ disagree; $7=$ agree $)$, attention to the game $(1=$ paid little attention; 7 = paid a lot of attention to the game), and mood (1 = feel bad; 7 = feel good $)$.

\section{Results and Discussion}

Manipulation Check and Control Measures. Separate 2 (power: high vs. low) $\times 2$ (game result: winning vs. losing) ANOVAs revealed that general risk-taking tendency, general liking of playing slots, and attention to the game were not different across conditions (all $F^{\prime}$ s $<1$ ). A 2 (power: high vs. low) $\times 2$ (game result: winning vs. losing) ANOVA on mood revealed that participants felt better after winning than losing $\left(M_{\text {win }}=5.54, M_{\text {lose }}=3.96 ; F(1,73)\right.$ $=26.04, p<.01)$; however, this finding did not explain the interaction effect between power and game result.

Hypothesis Testing. We predicted that participants with high power would be more likely to anthropomorphize the slot machine after winning than losing, whereas those with low power would show the opposite pattern. We conducted a 2 (power: high vs. low) $\times 2$ (game result: winning vs. losing) ANOVA in order to test this prediction. The interaction effect was significant $(F(1,73)=6.44, p=.01$; see fig. 8). Other effects were not significant. As predicted, planned contrasts revealed that participants with high power thought the machine they played looked more like a human after they won the game than after they lost $\left(M_{\text {win }}=6.55\right.$, 
FIGURE 7

MEASUREMENT ITEM FOR THE LEVEL OF ANTHROPOMORPHISM (EXPERIMENT 3)

Among the following two slot machines,

which one do you think is more similar to one you played with?

Click the number.

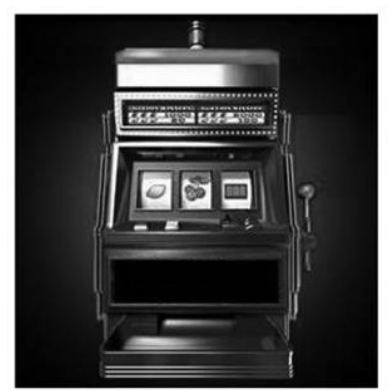

Similar to this

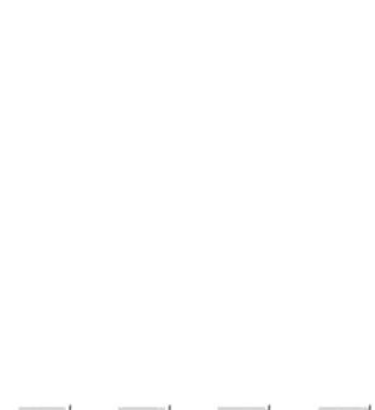

2

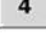

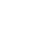

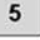

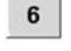

NotE.-Color version available as an online enhancement.

$\left.M_{\text {lose }}=4.62 ; F(1,73)=6.95, p=.01\right)$. In contrast, participants with low power indicated the slot machine they played looked more like a human after they lost the game, even though the effect did not reach a significant level $\left(M_{\text {win }}\right.$ $\left.=5.21, M_{\text {lose }}=6.00 ; F(1,73)=1.02, p=.31\right)$. Hence, participants appear to have inferred the presence of a human entity on the basis of the outcomes they received. In particular, participants appear to have anthropomorphized the machine, depending on their expectations about how a person would treat them on the basis of their level of powergiving them what they wanted or taking advantage of them.

\section{GENERAL DISCUSSION AND CONCLUSION}

Marketers often believe consumers will feel more positively toward their products if they see these products in human terms. For instance, toy makers try to create social bonds between children and their anthropomorphized toys (Turkle 2000). Car makers shape the headlights and grilles of cars to suggest a human face in order to appeal to buyers (Welsh 2006). Prior research largely supports these beliefs about the positive effects of anthropomorphism (for an exception, see Aggarwal and McGill [2007], study 3). For example, participants liked anthropomorphized robots more (Kiesler and Goetz 2002), liked programs with an anthropomorphized interface more (Burgoon et al. 2000), and showed greater improvement in their ability to learn software supported by anthropomorphic virtual assistants (Moreale and Watt 2004). However, our findings indicate that when an- thropomorphized entities bear risk, the effect of anthropomorphism may not be uniformly positive.

Specifically, our findings reveal that when entities bear risk, the effect of anthropomorphism is moderated by feelings of social power. Anthropomorphism increases risk perceptions for those with low power, whereas it decreases risk perception for those with high power. We trace these findings to people's application of social beliefs and expectations to anthropomorphized risk-bearing entities. Hence, high social

\section{FIGURE 8}

THE EFFECT OF POWER AND GAME RESULT ON ANTHROPOMORPHISM (EXPERIMENT 3)

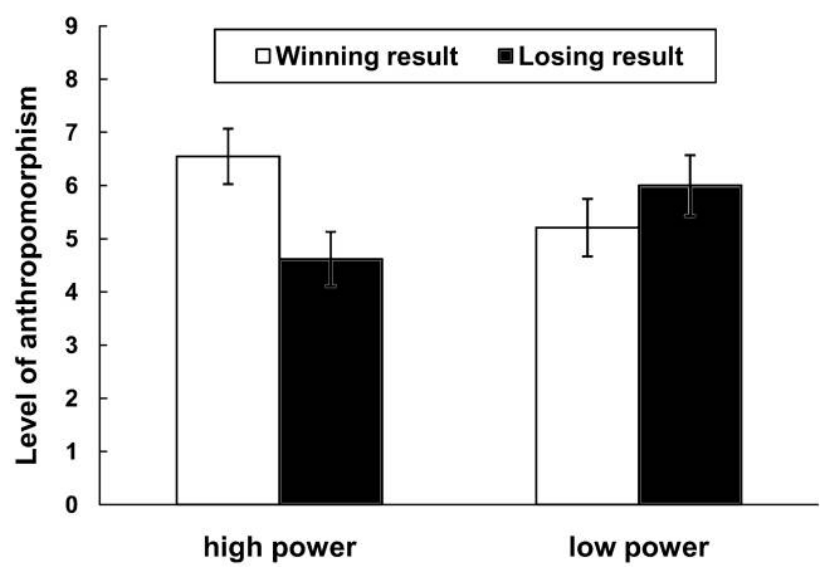


power makes people think they can control outcomes from anthropomorphized, risk-bearing entities, which in turn decreases risk perception. By contrast, lack of social power increases risk perception because people think they will not be able to control the entity to get their way. In other words, an anthropomorphized entity "behaves," and this behavior is subject to social rules, norms, and expectations. It can be cajoled, bullied, and sweet talked. A nonanthropomorphized entity "generates" outcomes and is not swayed by such antics.

Our findings, therefore, contribute to an emerging body of work that extends the understanding of anthropomorphism beyond an object-person metaphor triggered by humanlike physical features (Aggarwal 2004; Aggarwal and McGill 2007; Fournier 1998; Trampe, Stapel, and Siero 2007) to attribution of a humanlike mind to the anthropomorphized entity (Chandler and Schwarz 2010; Waytz et al. 2010). A consequence of this attribution is that the effect of anthropomorphism will not be the same for everybody. Rather, the effect of anthropomorphism will depend on what kind of social beliefs and perceptions people apply to nonhuman objects.

Hence, studies 1 and 2 show converging evidence that anthropomorphism increases the application of power by changing participants' perceptions of control. In study 1, humanizing a slot machine led participants with high power to perceive the game as less risky compared to a nonanthropomorphized machine, whereas humanizing the machine caused those with low power to perceive the game as riskier. This risk perception in turn negatively affected willingness to play the game. Those with high power were more willing to play the highly anthropomorphized machine, whereas those with low power were more willing to play the less (or non-) anthropomorphized machine. Study 2 replicates this interactive effect between power and anthropomorphism. However, different from study 1 , in which the slot machine is anthropomorphized with a humanlike appearance, we manipulated the degree of anthropomorphism in study 2 through the description of a skin cancer. We described the highly anthropomorphized skin cancer as if it were a criminal with an evil intention to harm people. Consistent with study 1 , people with high power thought the highly anthropomorphized skin cancer was less risky than skin cancer described in conventional terms. Participants with low power showed the opposite pattern. In addition to serving as a conceptual replication of study 1 , study 2 provides evidence about the process by which power perceptions moderate the effect of anthropomorphism. In particular, high power increases perceived control over anthropomorphized entities, while low power decreases perceived control, leading to the observed effects on risk perceptions.

An unexpected finding in our first two studies concerns the difference in willingness to play the slot machine (study 1) and the perceived susceptibility to the disease (study 2) between participants who were high and low in social power in the low-anthropomorphism condition. We had initially expected no effect of social power in the world of machines and diseases that were not anthropomorphized. The central tenet of our theory is that anthropomorphism activates social concerns such as power in nonsocial domains. That thinking, however, may have overlooked the possibility that people find places to feel comfortable and in charge. High social power plays out in the world of people or, as we have demonstrated, the world of anthropomorphized entities. However, low social power may lead people to feel better in a world precisely devoid of humanization. As a consequence, the low-social-power participants were more willing to play the machine and saw less risk in the disease when it was not humanized. The psychological mechanism by which being in a "comfort zone" plays out in the world of objects for low-power consumers is not clear. It might be a simple process by which low-power people contrast the uncomfortable, even bullying world of people with that of objects and so feel less risk in the latter. Instead of the effect being the result of a contrast effect, low-power people may use objects to make up for feeling powerless, along the lines of recent research by Rucker and Galinsky (2008), who found that people who are low in social power show more favorable attitudes toward products associated with status to compensate for their lower power. Our thoughts here are speculative, however, and future research is needed to explore the surprising influence of social power in nonsocial domains.

Our third study looked further into the prediction that anthropomorphized entities are understood through a rich social lens. Whereas the first two studies explored how anthropomorphism affects risk perception, the last study showed that risk perception can also affect the tendency to anthropomorphize. In this study, participants appeared to infer the presence of a human entity from their experiences with the slot machine. If people felt high power and the slot machine appeared to be giving them what they wanted (winning results), they anthropomorphized the object. People with low power, however, appeared more likely to anthropomorphize the object when it did not treat them well (i.e., provided losing results), although this effect was not significant.

This last study therefore extends the field's understanding of the sorts of factors that can affect anthropomorphism. Prior work shows that characteristics of the object, for example, appearance (e.g., Graham and Poulin-Dubois 1999; Guthrie 1993) and movement (Morewedge et al. 2007; Tremoulet and Feldman 2000) influence the tendency to anthropomorphize. Other work has looked at factors associated with the person, specifically, accessibility of the human schema and needs that may be filled by seeing the human in the nonhuman, such as the need for understanding or companionship (Epley et al. 2007). Our work suggests an interactive effect between object and person. The object is more likely to be anthropomorphized if the person's experiences with it align with expectations and experiences for how other people tend to interact with that person. Hence, a high-power person might find the human in good outcomes, as might a trusting person or someone who believes 
in the basic goodness of people. A low-power person, one who lacks trust or who believes other people are inherently unkind, may find the human in bad outcomes. To the extent that belief in a deity reflects the tendency to anthropomorphize, this finding might explain why some people see god in the joys of the world, whereas others find evidence of god in tragedies.

This research contributes to the literature on illusory control as well as on power. Whereas prior work documents the misuse of factors related to skill (e.g., rolling the die themselves, selecting lottery numbers themselves) in assessing risk, our work documents the misapplication of social factors. A subtle difference in the appearance of the slot machine was enough to increase the perception of the slot machine as human, which in turn affected risk perception. Similarly, describing a disease as having intentions made people see the disease in human terms, which in turn affected their beliefs about their ability to resist the disease or, if they did get it, to fight it off. Such a change in control perception is illusory because the objective chance of winning the game or catching the disease was the same, regardless of whether the machine and disease were presented as people. In addition, whereas most research on power has been conducted in a social context, this research shows that people may also apply their social power perceptions to nonhuman entities, provided they think of these entities in human terms.

This research further delivers important insights for gambling and health messages. When gambling, people are not uniformly more willing to interact with more humanlike machines, as a simplistic, positive view of the effect of anthropomorphism might suggest. Their power perception at that time also determines their intention to play the game. Considering that power perception is not chronically stable but is instead contextually flexible, marketers might be able to set strategies to increase or decrease people's willingness to play the game by changing their power perceptions or the appearance of machines. For example, a change in the height of the chair in front of the slot machine might change power perception. Our study revealed that a subtle change in the appearance of the slot machine can change anthropomorphism tendencies. Similar effects might occur for the perception of disease prevention messages. This research suggests that anthropomorphizing the disease can either increase or decrease risk perception, depending on perceived power, which in turn can influence willingness to adopt selfprotective actions (e.g., wearing sunscreen).

Our findings also imply a rich avenue for future research. First, what if the anthropomorphized entity is not a risk generator but a risk preventer? For example, instead of a disease, a vaccine could be anthropomorphized. In that case, will we think of the anthropomorphized vaccine as more effective and trustworthy or less? Going further, what if the anthropomorphized entity does not bear risk at all? We suspect that power may still play a role to the extent that people want to control the products (e.g., managing complex audiovisual equipment). Another avenue for future research might be to explore different types of social power or the interaction of power and communal and exchange relationship norms (Aggarwal 2004; Clark and Mills 1993) or social value orientation (Smeesters et al. 2003). For example, regardless of social power, consumers who see their relationship as more communal or who adopt a prosocial orientation may not see a smiling face as something to be exploited, whereas high-power consumers in an exchange relationship or who adopt a pro-self-orientation may try to take advantage of such a "good-natured" entity, acting more deferentially to one with a serious or even fierce expression. Also, future research could explore differences in the application of power, depending on specific characteristics of the anthropomorphized entity. For example, power perceptions may alter expectations and behavior toward objects anthropomorphized as male or female or as young or old. In sum, researchers may find consumers' responses to anthropomorphized entities, providing these entities are seen as having a humanlike mind, to be highly sensitive and as complex as those involving people.

\section{REFERENCES}

Aaker, Jennifer L. (1997), "Dimensions of Brand Personality," Journal of Marketing Research, 34 (August), 347-56.

$\rightarrow$ Aggarwal, Pankaj (2004), "The Effects of Brand Relationship Norms on Consumer Attitudes and Behavior," Journal of Consumer Research, 31 (June), 87-101.

Aggarwal, Pankaj and Ann L. McGill (2007), "Is That Car Smiling at Me? Schema Congruity as a Basis for Evaluating Anthropomorphized Products," Journal of Consumer Research, 34 (December), 468-79.

$\rightarrow$ Allen, Karen, Jim Blascovich, and Wendy B. Mendes (2002), "Cardiovascular Reactivity and the Presence of Pets, Friends, and Spouses: The Truth about Cats and Dogs," Psychosomatic Medicine, 64 (5), 727-39.

Bargh, John A., Paula Raymond, John B. Pryor, and Fritz Strack (1995), "Attractiveness of the Underling: An Automatic Power $\rightarrow$ Sex Association and Its Consequences for Sexual Harassment and Aggression," Journal of Personality and Social Psychology, 68 (5), 768-81.

Brinol, Pablo, Richard E. Petty, Carmen Valle, and Derek D. Rucker (2007), "The Effects of Message Recipients' Power before and after Persuasion: A Self-Validation Analysis," Journal of Personality and Social Psychology, 93 (6), 1040-53.

$\rightarrow$ Burgoon, Judee K., Joseph A. Bonito, Bjorn Bengtsson, Carl Cederberg, Magnus Lundeberg, and L. Allspach (2000), "Interactivity in Human-Computer Interaction: A Study of Credibility, Understanding, and Influence," Computers in Human Behavior 16 (6), 553-74.

$\rightarrow$ Chandler, Jesse and Norbert Schwarz (2010), "Use Does Not Wear Ragged the Fabric of Friendship: Thinking of Objects as Alive Makes People Less Willing to Replace Them," Journal of Consumer Psychology, 20 (2), 138-45.

Cheney, Dorothy and Robert M. Seyfarth (1990), How Monkeys See the World: Inside the Mind of Another Species, Chicago: University of Chicago Press.

Clark, Margaret S. and Judson Mills (1993), "The Difference between Communal and Exchange Relationships: What It Is and Is Not," Personality and Social Psychology Bulletin, 19 (December), 684-91. 
Copeland, John T. (1994), "Prophecies of Power: Motivational Implications of Social Power for Behavioral Confirmation," Journal of Personality and Social Psychology, 67 (2), 264-77.

Croizet, Jean-Claude and Theresa Claire (1998), "Extending the Concept of Stereotype Threat to Social Class: The Intellectual Underperformance of Students from Low Socioeconomic Backgrounds," Personality and Social Psychology Bulletin, 24 (6), 588-94.

Dépret, Eric and Susan T. Fiske (1993), "Social Cognition and Power: Some Cognitive Consequences of Social Structure as a Source of Control Deprivation," in Control Motivation and Social Cognition, ed. Gifford Weary, Faith Gleicher, and Kerry L. Marsh, New York: Springer, 176-202.

$\rightarrow$ Epley, Nicholas, Scott Akalis, Adam Waytz, and John T. Cacioppo (2008), "Creating Social Connection through Inferential Reproduction: Loneliness and Perceived Agency in Gadgets, Gods, and Greyhounds," Psychological Science, 19 (2), 114-20.

$\rightarrow$ Epley, Nicholas, Adam Waytz, Scott Akalis, and John T. Cacioppo (2008), "When We Need a Human: Motivational Determinants of Anthropomorphism," Social Cognition, 26 (2), 143-55.

$\rightarrow$ Epley, Nicholas, Adam Waytz, and John T. Cacioppo (2007), "On Seeing Human: A Three-Factor Theory of Anthropomorphism," Psychological Review, 114 (4), 864-86.

Fast, Nathanael J., Deborah H. Gruenfeld, Niro Sivanathan, and Adam D. Galinsky (2009), "Illusory Control: A Generative Force behind Power's Far-Reaching Effects," Psychological Science, 20 (4), 502-8.

$\rightarrow$ Fiske, Susan T. (1993), "Controlling Other People: The Impact of Power in Stereotyping," American Psychologist, 48 (6), 621-28.

$\rightarrow$ Fiske, Susan T. and Eric Dépret (1996), "Control, Interdependence and Power: Understanding Social Cognition in Its Social Context," European Review of Social Psychology, 7 (1), 31-61.

$\rightarrow$ Fournier, Susan (1998), "Consumers and Their Brands: Developing Relationship Theory in Consumer Research," Journal of Consumer Research, 24 (March), 343-73.

$\rightarrow$ Galinsky, Adam D., Deborah H. Gruenfeld, and Joe C. Magee (2003), "From Power to Action," Journal of Personality and Social Psychology, 85 (3), 453-66.

Graham, Susan A. and Diane Poulin-Dubois (1999), "Infants' Reliance on Shape to Generalize Novel Labels to Animate and Inanimate Objects," Journal of Child Language, 20 (June), 295-320.

Guthrie, Stewart E. (1993), Faces in the Clouds: A New Theory of Religion, New York: Oxford University Press.

Hauser, Marc D. (2000), Wild Minds: What Animals Really Think, New York: Holt.

$\rightarrow$ Keltner, Dacher, Deborah H. Gruenfeld, and Cameron Anderson (2003), "Power, Approach, and Inhibition," Psychological Review, 110 (2), 265-84.

Kiesler, Sara and Jennifer Goetz (2002), "Mental Models and Cooperation with Robotic Assistants," in Proceedings of Conference on Human Factors in Computing Systems, Minneapolis: ACM, 576-77.

$\rightarrow$ Langer, Ellen J. (1975), "The Illusion of Control," Journal of Personality and Social Psychology, 32 (2), 311-28.

$\rightarrow$ Leyens, Jacques-Philippe, Brezo P. Cortes, Stéphanie Demoulin, John F. Dovidio, Susan T. Fiske, Ruth Gaunt, Maria-Paola Paladino, Armando Rodriguez-Perez, Ramon Rodriguez-Torres, and Jeroen Vaes (2003), "Emotional Prejudice, Essentialism, and Nationalism," European Journal of Social Psychology, 33 (6), 703-17.

Moreale, Emanuela and Stuart Watt (2004), "An Agent-Based Approach to Mailing List Knowledge Management," in Agent-
Mediated Knowledge Management, ed. Ludger van Elst, Virginia Dignum, and Andreas Abecker, Lecture Notes in Artificial Intelligence 2926, New York: Springer, 118-29.

$\rightarrow$ Morewedge, Carey K., Jesse Preston, and Daniel M. Wegner (2007), "Timescale Bias in the Attribution of Mind," Journal of Personality and Social Psychology, 93 (1), 1-11.

Morgan, Conwy L. (1894), An Introduction to Comparative Psychology, London: Scott.

$\rightarrow$ Muller, Dominique, Charles M. Judd, and Vincent Y. Yzerbyt (2005), "When Moderation Is Mediated and Mediation Is Moderated," Journal of Personality and Social Psychology, 89 (6), 852-63.

Phillips, Barbara J. (1996), "Defining Trade Characters and Their Role in American Popular Culture," Journal of Popular Culture, 29 (Spring), 143-58.

Piaget, Jean (1929), The Child's Conception of the World, New York: Harcourt Brace Jovanovich.

$\rightarrow$ Rucker, Derek D. and Adam D. Galinsky (2008), "Desire to Acquire: Powerlessness and Compensatory Consumption," Journal of Consumer Research, 35 (2), 257-67.

$\rightarrow$ Siegel, Judith M. (1990), "Stressful Life Events and Use of Physician Services among the Elderly: The Moderating Role of Pet Ownership," Journal of Personality and Social Psychology, 58 (6), 1081-86.

$\rightarrow$ Smeesters, Dirk, Luk Warlop, Eddy van Avermaet, Olivier Corneille, and Vincent Yzerbyt (2003), "Do Not Prime Hawks with Doves: The Interplay of Construct Activation and Consistency of Social Value Orientation on Cooperative Behavior," Journal of Personality and Social Psychology, 84 (5), 972-87.

$\rightarrow$ Strickland, Lloyd H., Roy J. Lewicki, and Arnold M. Katz (1966), "Temporal Orientation and Perceived Control as Determinants of Risk-Taking," Journal of Experimental Social Psychology, 2, 143-51.

Thibaut, John W. and Harold H. Kelley (1959), The Social Psychology of Groups, New York: Wiley.

$\rightarrow$ Thompson, Suzanne C., Wade Armstrong, and Craig Thomas (1998), "Illusions of Control, Underestimations, and Accuracy: A Control Heuristic Explanation," Psychological Bulletin, 123 (2), 143-61.

$\rightarrow$ Trampe, Debra, Diederick A. Stapel, and Frans W. Siero (2007), "On Models and Vases: Body Dissatisfaction and Proneness to Social Comparison Effects," Journal of Personality and Social Psychology, 92 (1), 106-18.

$\rightarrow$ Tremoulet, Patrice D. and Jacob Feldman (2000), "Perception of Animacy from the Motion of a Single Object," Perception, 29 (8), 943-51.

Turkle, S. (2000), "When Toys Are Us," Forbes, October 2, 213-14.

Waytz, Adam, John Cacioppo, and Nicholas Epley (2010), "Who Sees Human? The Stability and Importance of Individual Differences in Anthropomorphism," Perspectives on Psychological Science, 5 (3), 219-32.

Welsh, Jonathan (2006), "Why Cars Got Angry," Wall Street Journal, March 10, W1-W10.

$\rightarrow$ Wohl, Michael J. A. and Michael E. Enzle (2002), “The Deployment of Personal Luck: Sympathetic Magic and Illusory Control in Games of Pure Chance," Personality and Social Psychology Bulletin, 28 (10), 1388-97.

Yoon, Carolyn, Angela H. Gutchess, Fred Feinberg, and Thad A. Polk (2006), “A Functional Magnetic Resonance Imaging Study of Neural Dissociations between Brand and Person Judgments," Journal of Consumer Research, 33 (1), 31-40. 